http://doi.org/10.4038/kjm.v6i1.7525

\title{
Building Relations between a Company and Consumers through Co- creation: Polish and Chinese Context
}

\author{
Wiścicka M. ${ }^{1}$ and Misiak-Kwit $\mathrm{S} .^{2}$ \\ The Institute of Management and Marketing, University of Szczecin, Poland \\ 1'mwiscicka@wneiz.pl \\ 2s.misiak@wneiz.pl
}

\begin{abstract}
The paper consists of two parts, i.e. theoretical and practical. The theoretical deliberations are devoted to the explanation of supporting the process of product co-creation. The practical part of this paper reports the findings of a study concerning the interest of young people in participation in co-creation in Poland and China. The aim of the article is finding whether the Polish and Chinese Y generation client's role understanding about the cocreation process and their feelings regarding the usefulness about the co-creation process. To gather primary data field survey method has been adopted with a structured questionnaire. The target group (population) of the survey was constituted by young people (generation Y) who, by virtue of their psycho-physical characteristics, are more prone to share their experience and engage in various activities. Percentage analysis has been applied to analysis the primary data. Based on the analysis, it can be concluded that the potential interest in the participation in co-creation is high among both groups of respondents (the Poles 56\%, the Chinese 90\%).
\end{abstract}

Keywords: Relationship, Co-creation process, Consumer, Poland, China, Management

\section{Introduction}

Building relations with stakeholders seems to be a standard behaviour in companies that operate throughout the today's markets. One of the forms of building relations is to invite a customer and other stakeholders to contribute to product co-creation, to assess the quality of the service or to share experience gained while using the products. The phenomenon of cooperation between companies and customers is not recent as in the past companies used to take advantage of customers' support during e.g. creation and modification of the product

(iD) http://orcid.org/0000-0001-9928-3335 
portfolio. The scale of such cooperation was small due to high costs and the application of mainly the opinion of expert customers, or engaging the customers in selected stages of product creation and not the whole process. As a result, the subject related literature provides examples of how such processes already operate in companies (Prahalad \& Ramaswamy, 2000; Ballantyne, 2004; Jaworski \& Kohli, 2006; Payneet al., 2008); still, there is a shortage of data related to the manner of completion of the co-creation process and the type of tools that are to be used during its implementation (Schare, 2004; Payneet al., 2008) with simultaneous growth of interest in the co-creation process (Webster, 2002). The process of co-creation means acting for the benefit of the company, which is based on the customer's knowledge and, in particular, the customer's experience.

The cooperation between the customer and the company relies on engaging a customer in various stages of the process of creation (Auh, 2003) providing, at the same time, the customer with the opportunity to familiarize with the company's activity. Opening up to the customer's support requires from the company accepting a new role, and acknowledging the fact that customers may need more data to create new values. Therefore, a dialog becomes indispensable in cooperation with the customer. Conducting a dialog, where the customer is assumed to be a member of the team, allows for opening up of a customer as well as recognizing the customer's needs and the motives of the customer's activity. On the one hand, a dialog helps the customer to get closer to the company, and on the other hand, the company is able to obtain more information than required by co-creation. A dialog with a cooperating customer may additionally provide data on possible negative feelings on the part of the customer, it may eliminate the effects of lack or insufficient satisfaction with consumption, and may also recognize customers' future needs.

A significant value of co-creation is the involvement of the customer in the cooperation with the company (Rogoziński, 2012), but there are also opinions voiced that it is the creation of a product for oneself that constitutes a value. Thus, it must be confirmed that a customer is an indispensable element of the said process, as the customer brings about a new value and makes a significant contribution to the creation of e.g. a new product (Fueller, 2009).

The growing interest and the development of co-creation would not be possible today if it had not been for the advancement of information technologies which have opened new possibilities for cooperation between the company and the customer. The examples are the Electronic Customer Relationship Management (ECRM), Social Customer Relationship 
Management (SCRM) and Customer Relationship Management 2.0 (CRM 2.0) systems. They serve for two-directional communication, which means that they are not only programmes but also tools for managing relations with customers. The development of the social media has also provided new possibilities of co-creation. This is particularly relevant at the moment when individualization of communication is most significant for customers. The above data is confirmed by the result of the survey conducted among Polish customers, where more than $76 \%$ of respondents appreciate individuation of communication and of an offer (Zupok, 2015).

The globalization-related changes in the world have resulted in smaller differences among customers in various parts of the world. An important factor differentiating between behaviours may be the social and cultural one. Does that mean that behaviours of young consumers from Europe and Asia will be different when considering the co-creation? Finding an answer to the question posed encouraged the authors of this article to conduct a pilot survey among the generation $\mathrm{Y}$ (Millennials). In the article two research problems were defined. The authors wanted to know whether the role of Polish and Chinese Y generation client's in co-creation process is fully understood. The second research problem regarding target group refer to the feeling whether their participation in the co-creation is useful.

In this article the emphasis is put on the presentation of research results from two countries: Poland and China. Those countries are representing different cultures, religions, traditions and levels of development measured by Human Development Index (HDI). Poland represents East-European culture with HDI equal 0.834 (very high level) while China represents Asian culture with HDI equal 0.719 (high level). The target group of the pilot survey consisted of young people (generation Y) who, by virtue of their psycho-physical characteristics, are more prone to share their experience and engage in various activities. The aim of the article is to find whether the Polish and Chinese Y generation client's role as well as their feelings regarding the usefulness in the co-creation process are fully understood.

The paper consists of two parts, a theoretical one and a practical one. The theoretical deliberations are devoted to the explanation of supporting the process of product co-creation. Further, it shows advantages of the process of building relations with customers. The empirical part is devoted to presenting the results of studies which show interest of young people in the participation in co-creation in Poland and China. 


\section{Process of Co-creation - Review of literature}

The co-creation process requires undertaking activities aimed at an establishment of an intensive interaction between the company and customers. The basis of such cooperation is constituted by a dialog between employees and the customer (Gronroos \& Voima, 2013). It should be emphasized that the activity and involvement of the customer in the co-creation process are voluntary (Fueller et al., 2009). The open attitude of the company to the client's proposals plus giving those proposals the same amount of consideration and interest as it is given to employees' proposals will be fundamental for creating an environment and atmosphere conducive to the customer's openness and involvement (Prahalad \& Ramaswamy, 2004).

Within recent years the necessity to build the so called 'open space' by the company has been more and more frequently presented in the subject related literature. The aim of the said space is to create a common value with the involvement of the customer. As a result, the company gains the customer's loyalty (Auh et al., 2007) as well as better adjustment of products to customers' expectations. Co-creation is, thus, an important tool for creating a relationship as: it strengthens bonds via cooperation with the customer, it increases the level of the customer's satisfaction, it identifies the customers involved, as well as increases the value discerned by customers in the product, which, in turn, leads to an increase in sale.

The co-creation process may be multi-faceted as, which has already been mentioned, it depends on the function assigned to the customer open to cooperation with the company. Four basic groups of customization might be distinguished i.e. collaborative, adaptive, transparent, and cosmetic. The first group provides individual clients with an exact article as it conducts a dialog with the customer with regard to the customer's expectations. The second type of cooperation is characterized by offering a standard product, which the customer himself/herself adjusts to his/her needs. The third group consists of unique products that are adjusted, without the customer's knowledge, to the customer's needs. The last group is based solely on the differentiation of the manner of the product sale to various clients (Charles, 2014). In practice, the cooperation with the customer applies such systems as e.g. Japanese systems of participative management, lean production, quality circles, and Six Sigma.C. More and more often companies use social media and websites to invite costumers to trade ideas and experience (Ramaswamy \& Gouillart, 2010). Owing to the target directed at gaining experience by stakeholders, the company may obtain valuable guidelines to reduce 
costs, to find a new business model, or a new source of income.

It might seem that the majority of companies care about the types of experience provided by their products and services. In reality, however, no significant attention is drawn to customers' experiences. This may stem from the fact that clients do not have any real impact on co-creating their sensations, and managers of companies do not keep up with changes and they choose to pursue their own hierarchical systems. Additionally, they do not want anyone else to define and create customers' experiences (Grygier, et al., 2011).

Managers also wrongly assess motives that drive clients when establishing contact with an enterprise by e.g. reviewing the company's profile via the social media. The study shows that clients mostly look for promotions and discounts and the possibility of writing and reading about products. Managers believe that the form of contact held through the social media results mainly from searching general data, novelties or exceptional information (IBM Report, 2011). Discrepancies in opinions confirm little awareness of customer's expectations in that field. While it is thanks to the availability of new technologies, such as e.g. CRM 2.0 programme, the co-creation process and exchange of experience is simplified and allows for more efficient management of relations with the customer (Rajoya, 2015). The key significance of activities within the co-creation process is the acknowledgement of the role of the client: otherwise an honest and fruitful cooperation would not be possible.

It is also emphasized that the willingness of clients to cooperate in the product co-creation is a domain of young people as participation in such process is a form of individualization for them (of being singled out). They are not afraid of new technologies, and they willingly look for information on interesting products. They naturally gather around and focus on mutual interests, skills and experience, and they willingly undertake challenges for which they find non-standard solutions (European Commission, 2015).

As confirmed by the data presented in this part of the article, the application of co-creation is significant in building lasting relations with the customer, viewed as a significant tool of competitive advantage. Therefore, it would be essential to analyse the way the process is put into practice. The authors of the article have undertaken research aimed at the assessment of the level of awareness and interest in the participation in the co-creation process among young consumers from countries representing a different level of economic progress.

The further part of the article presents a summary of the results of the author's own research 
conducted within the said scope.

\section{Methods and Findings}

This part describes the research methodology and data analysis. The aim of the conducted pilot study was to realize the interest of young people in the participation in co-creation in different countries, such as Poland, Germany, Romania, China, Georgia and Sri Lanka. In this article the authors have decided to compare research results for China and Poland. The reason for such a decision was to compare two countries with different cultures, religions, traditions and levels of development measured by Human Development Index (HDI).

According to the authors, it is important to notice differences and similarities between European and Asian countries and comparison of the research results from both countries allows to discover them. Discovering similarities and differences is crucial concerning future cooperation between those countries. Questionnaire based survey in China and Poland was conducted from June till September 2016. In the questionnaire the authors used descriptive questions where respondents were asked to answer in a five point Likert scale. Ass the analysis tool, Microsoft excel was used. To ensure that there were no missing values a preliminary data and a recheck was carried out. The responses from two countries were compared by the usage of pivot tables. Tables are described based on the aggregate mean values for two countries. The study was conducted among young people who, by virtue of their psycho-physical characteristics, are more open to share their experience and engage in various activities. The characteristics of the surveyed group has been presented in the table 1 .

Table 1: Characteristics of the surveyed group participating in research in Poland and in China

\begin{tabular}{|c|c|c|}
\hline & Poland & China \\
\hline \multicolumn{3}{|c|}{ Gender } \\
\hline Male & $25 \%$ & $17 \%$ \\
\hline Female & $75 \%$ & $83 \%$ \\
\hline \multicolumn{3}{|c|}{ Place of residence } \\
\hline Uural areas & $27 \%$ & $37 \%$ \\
\hline & $73 \%$ & $63 \%$ \\
\hline
\end{tabular}




\begin{tabular}{|c|c|c|}
\hline $\mathbf{1 9 8 9}$ or earlier & $2 \%$ & $4 \%$ \\
\hline $\mathbf{1 9 9 0}$ & $4 \%$ & $2 \%$ \\
\hline $\mathbf{1 9 9 1}$ & $0 \%$ & $6 \%$ \\
\hline $\mathbf{1 9 9 2}$ & $7 \%$ & $15 \%$ \\
\hline $\mathbf{1 9 9 3}$ & $21 \%$ & $15 \%$ \\
\hline $\mathbf{1 9 9 4}$ & $32 \%$ & $6 \%$ \\
\hline $\mathbf{1 9 9 5}$ & $32 \%$ & $4 \%$ \\
\hline $\mathbf{1 9 9 6}$ or later & $2 \%$ & $48 \%$ \\
\hline
\end{tabular}

Source: own collaboration based on survey results

The sample size was 226. Multistage mixed sampling method was used during sample selection. Universities from each country were selected for the convenience and a simple random sample was selected from the undergraduates of Guangdong University of Foreign Studies and Ningbo University, China and University of Szczecin from Poland to represent the Y Generation of each country. In the survey conducted in Poland 133 persons participated, with 124 questionnaires being filled in correctly. The surveyed group was mainly represented by women (75\%), persons living in urban areas $(73 \%)$ and persons who were born in 1993 or after 1993 (87\%). In China, 102 questionnaires were accepted (out of 103). As shown in the table, $63 \%$ of the surveyed group was living in urban areas. When analysing the data shown in table 1 it can be noted that these were mainly women (83\%) who participated in the study. Furthermore, during the study $48 \%$ of respondents was under the age of 20. Regardless of the country, the surveyed group consisted mainly of women who were living in urban areas. The biggest difference was the age - the people who took part in the survey in China were statistically younger than in Poland. The authors believe that the age difference has no greater impact on the differences in answers as all respondents belong to the group of consumers of the generation Y. The representatives of this group are open to new technologies, they cannot normally function without high-tech, they know what their priorities are, they are aware of high quality and they are willing to enjoy life (Ravindranath, 2016).

The involvement of young people in the co-creation process in chosen countries seems to be an interesting issue that should be discussed. For this purpose, young people were asked to indicate whether they had been participating in co-creation or not. According to the answers given, only $7 \%$ of respondents in Poland and $12 \%$ in China had been invited to participate in 
that process. In China, only women were the ones who had been ever co-creating; moreover, $13 \%$ of respondents living in urban areas and $11 \%$ of respondents living in rural areas have participated in co-creation. Among the respondents in Poland, $13 \%$ of man and $4 \%$ of women had been co-creating; furthermore, $7 \%$ had been living in urban areas and $6 \%$ in rural ones. Further details concerning co-creation process are presented in table 2.

Table 2: The involvement of young people in the co-creation process in Poland and in China

\begin{tabular}{|c|c|c|}
\hline & Poland & China \\
\hline \multicolumn{3}{|c|}{ Invitation to participate in co-creation process } \\
\hline Yes & $7 \%$ & $12 \%$ \\
\hline No & $93 \%$ & $88 \%$ \\
\hline \multicolumn{3}{|c|}{ Groups of product that have been co-created } \\
\hline Food and Drink & $6 \%$ & $6 \%$ \\
\hline IT programs & $3 \%$ & $6 \%$ \\
\hline Computer games & $4 \%$ & $4 \%$ \\
\hline Mobile phones & $2 \%$ & $2 \%$ \\
\hline Computers & $2 \%$ & $1 \%$ \\
\hline Clothes & $3 \%$ & $6 \%$ \\
\hline Shoes & $4 \%$ & $4 \%$ \\
\hline Domestic appliances & $3 \%$ & $4 \%$ \\
\hline Books & $3 \%$ & $7 \%$ \\
\hline Service & $3 \%$ & $8 \%$ \\
\hline Others & $0 \%$ & $2 \%$ \\
\hline \multicolumn{3}{|c|}{ Elements that have been co-created } \\
\hline Product packaging & $3 \%$ & $8 \%$ \\
\hline $\begin{array}{c}\text { Product function } \\
\text { (usability) }\end{array}$ & $2 \%$ & $8 \%$ \\
\hline Product feature & $4 \%$ & $8 \%$ \\
\hline Price charge & $3 \%$ & $9 \%$ \\
\hline Promotion campaign & $2 \%$ & $8 \%$ \\
\hline New logo & $2 \%$ & $7 \%$ \\
\hline Service & $0 \%$ & $8 \%$ \\
\hline
\end{tabular}




\begin{tabular}{|c|c|c|}
\hline Others & $1 \%$ & $1 \%$ \\
\hline \multicolumn{3}{|c|}{ The willingness to participate in co-creation again } \\
\hline Yes & $56 \%$ & $90 \%$ \\
\hline No & $44 \%$ & $10 \%$ \\
\hline
\end{tabular}

Source: own collaboration based on the survey results

There is no special group of product that had been co-created more often than other groups this in one of the conclusions that arises from the analysis provided in table 2. The group of product that had been co-created slightly more often than the others is Food and Drink in Poland and Services and Books in China. Altogether, the surveyed young people had been co-creating 37 times in Poland and 51 times in China. In $22 \%$ of all described cases in Poland and China, the respondents had been co-creating the product more than three times. The respondents were also asked to specify the type of elements they had been co-creating. In China, more often than in Poland, one respondent had been involved in co-creation of more than one element. There is no specific element that had been co-created more often than other ones. Two elements that had been indicated marginally more often are Product feature in Poland and Price charge in China.

As shown in table 2, the co-creation had been generally assessed positively. Many more respondents showed the willingness to participate in co-creation again in China (90\%) than in Poland (56\%). There was only one reason why the person from China did not want to cocreate in the future and the reason was not getting any feedback from the company. The reasons that had been listed in Poland are: the lack of time, the fact that a company did not express gratitude for the information provided, getting no feedback and no information whether the company implemented the customer's ideas. Such data should be of utmost importance for companies who have decided to co-create together with the customer. The results show errors made by companies during the process, and the awareness of errors and consideration given will improve the quality of the co-creation process in future.

Most of the respondents had not participated in co-creation. Thus, it would be worth knowing the reasons that may encourage young people to engage in the analysing process. These reasons are presented in figure 1 as average ranks assigned to reasons proposed by respondents, whereby the higher the average position, the more interesting the reason. The respondents had the possibility to assess the reasons in the scale from 1 to 5 . 


\begin{tabular}{|l|l|}
\hline \multicolumn{1}{|c|}{ Poland } \\
\hline $\begin{array}{l}\text { Getting the invitation to a } \\
\text { sample version of new } \\
\text { product }(3,35)\end{array}$ \\
\hline Getting a prize $(3,34)$ \\
\hline $\begin{array}{l}\text { One's own satisfaction } \\
(3,23)\end{array}$ \\
\hline $\begin{array}{l}\text { Prestige attached to } \\
\text { cooperating with a } \\
\text { company }(3,19)\end{array}$ \\
\hline $\begin{array}{l}\text { The invitation to improving favourite brand, so I } \\
\text { wroduct usability }(3,08) \\
(3,70)\end{array}$ \\
\hline $\begin{array}{l}\text { The chance to generate } \\
\text { ideas for brands is } \\
\text { absolutely fantastic and } \\
\text { challenging }(3,11)\end{array}$ \\
\hline $\begin{array}{l}\text { It is my favourite brand, so I } \\
\text { would eagerly participate } \\
\text { ideas for brands is } \\
\text { absolutely fantastic and } \\
\text { challenging }(3,35)\end{array}$ \\
\hline $\begin{array}{l}\text { The invitation to improving } \\
\text { product usability }(3,21)\end{array}$ \\
\hline $\begin{array}{l}\text { Others }(0,28) \\
(3,20)\end{array}$ \\
\hline
\end{tabular}

Fig. 1: Average rank assigned to reasons that would encourage young people to participate in the co-creation process by the surveyed young people in Poland and in

\section{China}

Source: own collaboration based on the survey results

When analysing the data shown in figure 1 it can be noted that the reasons that would encourage young people to participate in the co-creation are a bit different in Poland and in China. Young people living in Poland would like to get some additional gratitude like a sample version of a new product (52\% of respondents agree or strongly agree with that statement; average rank: 3,35$)$ or prize (56\% of respondents, average rank: 3,34$)$. The answer that got the highest average rank in China, got the lowest rank in Poland. If young people in China had the possibility to cooperate with their favourite company, they would eagerly do so without any additional motivators $-61 \%$ of Chinese respondents agree or strongly agree with this statement (average rank: 3,7). Moreover, 37\% of respondents from China disagree or strongly disagree with the statement that the reason to encourage them to participate would be the prestige attached to cooperating with a company (average rank: 3,0). 
Another important issue connected with the analysed topic pertained to the meaning of cocreation. Average ranks assigned to proposed meanings of co-creation by the young people are shown in figure 2, whereby the higher the average position, the more important the meaning. The respondents had the possibility to assess the reasons in the scale from 1 to 5 .

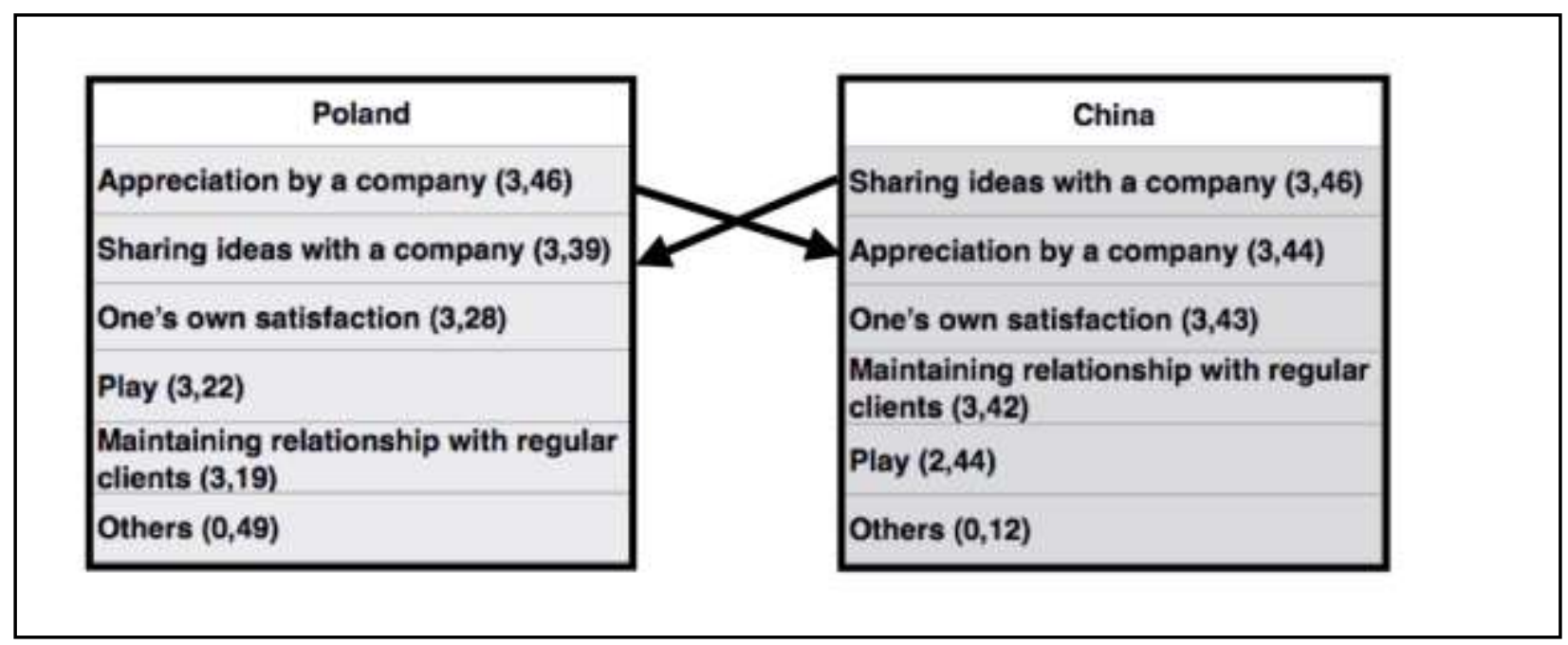

Fig. 2: Average rank assigned to the meaning of the co-creation by the surveyed young people in Poland and in China

Source: own collaboration based on the survey results

As shown in figure 2 young people in China treat co-creation process seriously; 'Play', as the meaning of co-creation received the lowest rank $(2,44)$ among Chinese respondents. Only $26 \%$ respondents agree or strongly agree that the co-creation is a 'play' for them. The average rank of the rest of the answers is very similar. $61 \%$ of Chinese respondents agree or strongly agree that the co-creation means 'sharing ideas with a company' (average rank: 3,46). According to the respondents from Poland, possibility to co-create is a way of showing the appreciation by a company ( $60 \%$ of Polish respondents agree or strongly agree with that statement; average rank: 3,46). However, the ranks assigned by young people in China and in Poland are similar.

\section{Discussion and Conclusions}

The analysis of the subject-related literature allows for drawing some basic conclusions. The first one constitutes the necessity of searching activities enabling the maintenance of long- 
term relations with a customer. One of the tools of creating and maintaining such relations is the process of co-creation. The process, however, is most frequently described in the subjectrelated literature as experience gained by the company. It lacks, however, theoretical guidelines defining the manner of implementation and the application of co-creation.

Another conclusion that might be drawn on the basis of the analysis of the subject-related literature is the role of a dialog. The effectiveness of the co-creation process depends on the openness to conduct a dialog with a customer and a successful dialog should be characterized by openness, trust and honesty.

The interest in the co-creation process has increased throughout years. The key factor affecting the increase is the development of new technologies and the social media. According to the authors, this constitutes another important conclusion drawn on the basis of the literature-related analysis.

The aim of this article was to present similarities and differences in building relations through co-creation in China and Poland. One of the most important conclusions is that if one person has been involved in co-creation then he/she has been involved approximately four times in co-creation of different groups of products and various elements. This situation is similar in both countries, i.e. China and Poland. This means that people involved are open to further cooperation and strengthening the relationships with the company.

Only a minority of the survey participants have been invited to participate in the co-creation process. This may lead to a conclusion that relatively few firms are interested in building relations between them and their young consumers through co-creation.

As far as differences are concerned, the fact that can be pointed out is that respondents in China have been co-creating more often than respondents in Poland. The most visible difference appears in the assessment of the co-creation process. Many more respondents from China (than form Poland) show their willingness to participate in co-creation in future. This might be one of the reasons why co-creation has more potential for growth in China than in Poland (not to mention statistics considering both countries such as population). The other reason is that young people living in China do not need to get any additional payment from company to engage into the co-creation process. They want to cooperate with the company if they have a chance to participate in building their favourite brand while young people in Poland expect to get a concrete gratitude. However, there is a potential to involve young 
people from both countries in co-creation process. The reasons why people from Poland are less interested than people from China in the co-creation process include the lack of time, the fact that a company did not express thanks for the information provided, getting no feedback and no information whether the company implemented the customer's ideas. This allows to draw a conclusion that companies from Poland have made more mistakes in the communication process with customers than companies from China.

The study conducted allows for confirming the assumed hypothesis that despite significant cultural differences, the co-creation phenomenon is too recent to enjoy huge popularity among young people representing the Asian and the European cultures. If, however, young people are engaged in the analysed process, they evaluate it positively and they participate in the process not only once but more frequently, and with a bigger number of elements.

The potential interest in the participation in co-creation is high among both groups of respondents (the Poles 56\%, the Chinese 90\%). On the basis of such data, the second hypothesis may be confirmed stating that despite significant cultural differences, young people (generation Y) are interested in co-creation with companies in similar areas. The cocreation phenomenon, thus, constitutes a chance to create lasting relations with a young customer and companies should become aware that the generation $\mathrm{Y}$ would be willing to participate in co-creation. It is also worth noticing that the most frequently created groups of products include Food and Drink in Poland and Books in China.

Despite differences existing between countries, the analysing process looks similar. Starting a new relation with a customer through a proposal to create a product together with a company seems to be a good beginning and a possibility of a long-term relationship. Therefore, it appears advisable to analyse this process in detail and among a bigger number of respondents, not only from Poland and China but also from other countries.

Based on the above mentioned research problem, there is a possibility to enrich this research study by develop hypothesis and conduct the independent $t$ test. According to that the hypothesis can be written as follows:

Null hypothesis:

H01 : The Polish and Chinese Y generation clients have fully understand about clients role in co-creation process.

H02 : The Polish and Chinese Y generation clients have the feeling that participating to the 
co-creation is useful.

Alternative hypothesis:

H1 : The Polish and Chinese Y generation clients have not fully understand about clients role in co-creation process.

$\mathrm{H} 2$ : The Polish and Chinese Y generation clients have not the feeling that participating to the co-creation is useful.

In order to test the hypothesis by applying independent $t$ test the field survey should be conduct again with the five point Likert scale questionnaire.

\section{References}

Adrian F. Payne, Kaj Storbacka, Pennie Frow, (2008) Managing the co-creation of value, Journal of the Academic Marketing Science, p.83-85.

Auh S., (2007) Co-production and customer loyalty in financial services, Journal of Retailing, t.83 no.3.

Ballantyne, D., (2004) Dialogue and its role in the development of relationship specific knowledge. Journal of Business and Industrial Marketing, 19(2), p.114-123.

Charles N., (2014) 44 Success Secrets - 44 Most Asked Questions On Co-creation - What You Need To Know, Emereo Publishing.

Füller, J., Mühlbacher H., Matzler K., Jawecki G., (2009) Consumer Empowerment Through Internet-Based Co-creation, Journal of Management Information System, part 26, no.3.

Gronroos Ch., Voima P., (2013) Critical service logic: making sense of value creation and cocreation, Journal of the Academy of Marketing Science, no. 41.

Prahalad, C.K., Ramaswamy, V. (2000) Co-opting customer competence. Harvard Business Review.

Prahalad C.K., Ramaswamy V., (2004) The future of competition: co-creating unique value with customers, Harvard Business School Press, Boston.

Ramaswamy V., (2009) Co-creation of Value -Towards an Expanded Paradigm of Value Creation, Marketing Review St. Gallen, no.6. 
Ravindranath P., (2016) An empirical study on the importance of technology quality in creating brand preference among the Generation Y (Gen-Y) banking customers in Kerala, International Journal of Scientific Research \& Management Studies, no 09.

Rogoziński K., (2012) Zarządzanie wartością z klientem, Wolters Kluwer, Warszawa.

Schrage, M., (1995) Customer relations. Harvard Business Review, July/August, p.154-156.

Webster, F. E., (2002) Marketing management in changing times. Marketing Management, January/February, no 11, p. 1-17.

Zupok S., (2015) Kreowanie wartości dla klienta, Ekonomika i Organizacja Przedsiębiorstw, no 3 , p.46- 57. 